\title{
FACTORS INFLUENCING ENTERPRISE TRAINING: EVIDENCE FROM NEW ZEALAND
}

\author{
Stephen Blumenfeld \\ Victoria University of Wellington \\ Ashish Malik \\ The Open Polytechnic of New Zealand
}

\begin{abstract}
Information gleaned from the 2003 New Zealand Skills and Training Survey, conducted as a part of a joint study by Business New Zealand and Industry Training Federation and supported by the Nesw Zealand Department of Labour's Future of Work Contestable Fund, are used to assess, within the New Zealand context, the relative impact various factors generally known to influence provision of training in other countries. For the purposes of this paper, factors suggested by academic literature as likely determinants of training are grouped under two broad categories: enterprise characteristics and employee demographics. Measures of these influences are specified as independent variables in linear and logistic regressions used to derive estimates of the extent to which each factor affects various aspects of skills development and training in New Zealand enterprises. Indices of training volume and training diversity, which gauge the nature and extent of training in these organizations, are employed as dependent variables in these regressions. Results of this analysis suggest, among other things, that firm size and casualisation of workforce are the most significant factors affecting the provision of training by New Zealand employers.
\end{abstract}

\section{Introduction}

Over the previous two decades, in both developed and developing economies, most organisations have faced growing pressure from both domestic and global competition. In many industries, this has resulted in the enhancement of technology, which has, in turn, increased the relative demand for skilled labour. Employers have frequently responded to this changing environment and their growing need for a more skilled labour force by placing greater emphasis on employee training and development (Stevens and Walsh 1991).

Using data from the 2003 Business New Zealand Skills and Training Survey, this study offers an analysis of the significance of two broad categories of explanatory variables - organizational characteristics and employee demographics - on the nature and extent of training supported by New Zealand employers. In particular, the analysis described herein considers the impact of such factors as years of operation, organisation size, industry sector, casualisation of work, gender composition of the workforce, and the level and mix of qualifications and skills on training volume and the diversity of training arrangements. The former is measured using an index which combines the relative proportion of payroll spent on training and the share of employees trained, while the latter is gauged by an index encompassing both the types of training supported and the means by which that training is offered.

\section{Explaining Enterprise Training}

As is the case in the broader field of HRM, countless perspectives of enterprise training have been advanced in the literature on human resource development (HRD) over the past two decades. Keenoy (1999) draws an analogy between the proliferation of theories of human resource management (HRM) since the mid-1980s and the manner by which an individual's perception is influenced by the lens through which he or she views a given phenomenon. This would suggest that enterprise training and HRD are best understood from a multidisciplinary approach, with each discipline offering a valuable lens through which one can assess the efficacy of the various approaches to training and development (Smith and Hayton, 1999; Garavan et al, 2000; Sambrook and Stewart, 1998; Mankin, 2001; Weinberger, 1998). This also suggests that the way in which human resource managers view training, development, education and learning influences the manner by which these activities are organized and managed within an organisation.

Recently, human resource management experts have come to focus on the need to make organisations more competitive and the concomitant need for workplace reorganisation. Hence, most attempts to delineate factors that influence enterprise training and employee development have focused exclusively on the role of HRD in organisations undergoing change (OECD and CERI, 1986, 1988). Nevertheless, given the growing perception of the importance of training development as a source of competitive advantage for organisations, since the early 1990s, HRD is no longer viewed as a subset of HRM but, rather, is now seen as an emerging body of knowledge in and of itself. For that matter, others suggest training and development are best viewed as distinct points along a continuum extending from the 'traditional' training function, encompassing learning exercises provided exclusively to a core group of employees and with an eye toward enhancing the 
organisation's supply of skilled labour, to the 'learning organisation', in which all learning activities are strategically linked and line managers and the employees themselves are responsible for carrying out those activities (Garavan, 1997a).

\section{Models of Enterprise Training}

A plethora of models establishing the factors that influence enterprise training have been advanced in the HRD literature. Researchers at the University of Warwick, for instance, grouped factors influencing the provision of training into two broad categories: 'triggers' and 'stabilisers' (Sparrow and Pettigrew, 1985; Hendry \& Pettigrew 1989). The former are factors that motivate or drive training, while the latter are factors that establish or lead to the implementation of training. This model further supports the notion that training is stabilised through a combination of factors both internal and external to the organisation. Internal stabilisers include the organisation's training infrastructure, its budgetary constraint, and its industrial relations environment. Stabilisers external to the organisation include the demand for and supply of skilled labour, as well as government regulation and public and private support for training.

Hayton et al. (1996) point to three groups of factors affecting skill formation and the provision of training in Australian enterprises: training drivers, environmental factors and mediating factors. The first category is comprised of factors internal to the organisation that 'trigger' commitment to training. These include workplace reorganization, technological change, introduction of quality protocols, provisions of industrial awards or agreements, performance appraisal systems, and business planning. Like those factors that drive investment in training by an organisation, mediating factors are internal to the organisation and include the size of the enterprise, occupational structure, and industry type, training infrastructure, the level of training decision making and senior management commitment to training. Environmental factors that affect the provision of enterprise training, though, are external to the organisation. These include the structure and competitive nature of the organisation's product and labour markets and government regulation.

Ridoutt et al. (2002) contend that, as not all of the factors stated in the Hayton et al (1996) model will be universally applicable and, depending on the type of industry chosen and the wider environment under which it operates, it is possible to exclude one or more drivers and/or mediating factors for each of these outputs. suggest a means of simplifying this model by limiting the outputs to two forms of training activity: training volume and the nature of training. These authors, therefore, offer a means of simplifying this model which entails limiting the outputs to two measures of broad training activity: training volume and the nature of training provided. The former gauges the extent of training being undertaken in an organisation and is specified in the authors' regression analysis as an index comprised of two components: the percentage of payroll spent on training and the share of the organisation's employees involved in training. The latter encompasses several factors, including training reform engagement, reliance on external providers, and training formalisation.

\section{Data and Methods}

This study uses data derived from the Business New Zealand Skills and Training Survey, which was by Business New Zealand (formerly New Zealand Employers' Federation), the leading national business organisation in New Zealand, in conjunction with the Industry Training Federation, a membership-based organisation representing Industry Training Organisations in New Zealand, and the New Zealand Department of Labour. The Survey was funded by the New Zealand Department of Labour's Future of Work research programme with the objective of improving knowledge about the level and nature of enterprise-based training, as well as the drivers of and barriers to training in New Zealand workplace (Business New Zealand and ITF, 2003).

Respondents to this survey comprise firms and enterprises on the membership rolls of regional associations constituting Business New Zealand. Measures of the nature of training of training activity carried out in the enterprise that can be derived from this survey include the diversity of training arrangements, formalization and decentralisation of training, training infrastructure, and types of training provided. Those factors which can be used to gauge the extent of training supported by these organisations include training expenditure as a percentage of payroll, the share of employees trained and the number of person-days of training provided. The survey also yields indicators of various market, workplace, and employee characteristics. The latter include level of skills and qualifications gained and job characteristics, such as skill requirements and the nature of tasks performed.

The Business New Zealand survey sample was stratified to ensure inclusion of a representative number of relatively small, medium and large size enterprises across all regions of the country (Business New Zealand and ITF, 2003). Nevertheless, since it is limited to members of Business New Zealand, it cannot be said that the sample is necessarily representative of all New Zealand enterprises. For this reason, responses to this survey and findings from the analysis of these data are not necessarily generalisable to the whole of New Zealand. The survey does, however, offer valuable insights into the nature and extent of training activities carried out within the responding organisations.

Following Hayton et al. (1996) and Ridoutt et al (2002), the measure of training diversity employed in this analysis gauges the extent to which an enterprise makes use of a range of formal and informal training activity options. This measure accounts for training effort, notwithstanding the sheer volume of training.

In addition, the survey instrument was not constructed with an eye toward this specific analysis of these data. This, then, underscores the fact that this analysis is also 
limited by the wording and range of questions asked of the respondents. In general, survey questions could have been better constructed to yield continuous measures of certain variables, as in the case of years of operation, rather than discrete, categorical variables. Nevertheless, in spite of these limitations in the data, there remains significant variation in these measures to indicate statistically significant differences between respondents across a number of those items derived from the Business New Zealand Survey and employed in this analysis.

\section{Measures of Training Investment}

The statistical analysis used in this study employs two measures of investment in training, each specified as the dependent variable in separate regression equations. The first of these measures gauges training volume; the second assesses training diversity. In each case, a composite index is constructed using a series of items derived from the Business New Zealand Skills and Training Survey. Following the methodology employed by Ridoutt et al (2002), each composite measure is derived by combining responses to various survey questions and allocating an index number ranging from 0 to 5 over the range of values. A composite score of 5 , therefore, is assigned to any organizations that offers, in the case of training diversity, the widest variety of training options to its employees or, in the case of training volume, exhausts all of its available resources on training.

Our index of training volume is calculated as the sum of the proportion of employees trained plus the share of total payroll spent on training. These measures are based on responses to two open-ended questions from the Business New Zealand Skills and Training Survey. In the first instance, respondents were asked, "How much did your enterprise spend on skill development and training in the last 12 months, as a percentage of your payroll?" With regard to the latter, respondents were queried, "What percentage of your employees have undergone training in the last 12 months?" For purposes of this analysis, responses to these two questions, both percentages, are each weighted by a factor of 2.5 .

In terms of measuring training diversity, a composite index drawn from combined scores in a series of multipart questions is calculated by summing the number of subjects covered in training supported by the organisation plus the number of methods used in the provision of that training. This, again, closely corresponds to the method of gauging these factors employed by Ridoutt et al. (2002) at the National Centre for Vocational Education Research (NCVER) in their the study of Australian firms conducted for the Australian National Training Authority. This composite index is comprised of a total of 15 items: 11 subjects covered in training supported by the organisation and 4 means of providing this training.

Virtually all of the New Zealand organisations surveyed support training in at least one area. Findings derived from the Business New Zealand Skills and Training Survey indicate that greater than four out of five respondents' enterprises provide specific technical and/or skills-based training., and more than three-quarters of the organisations surveyed offer training in areas related to health and safety. Computing and information and communications technology skill development is also supported by the majority of these employers, while close to half of the organisations included in this survey provide management and supervisory skills training.

With regard to the means by which training is provided, skill development may take place within the organisation, outside of the organisation, or at the industry level. The vast majority of respondents to the Business New Zealand Skills and Training Survey reported using external courses and programmes. Most indicated that their organisation also relied on in-house training programmes, and about two-thirds mentioned employing one-off seminars as a means of skill development (Business New Zealand and ITF, 2003). It is, nevertheless, important to note in that, in practice, the provision of training will typically include both formal and informal training. As has been discussed in the literature, the measurement of the latter is, by its very nature, problematic. Given that larger organisations are said to be more likely to account for these less formal types of training (Field, 1998) and the fact that the the sample used in this analysis is comprised of relatively large organisations the sample used in this analysis, this is issue is not considered to have a significant bearing on the results of this study.

\section{Measures of Factors Influencing Training}

The Business New Zealand Skills and Training Survey also yields a number of measures of factors suggested in the literature on training and development as possible influences on the provision of training by organisations. Extant literature, for instance, suggests that workforce permanency encourages a higher investment in training (Blundell et al., 1996; Groot, 1997). In this regard, Ridoutt et al. (2002) offer evidence that workforce permanence is a significant and positive influence on training diversity, among other outcomes related to training and development of employees, such as external reliance, formalisation, learning support and individualisation. No relationship was observed in that research, however, between workforce permanency and the volume of training. Nevertheless, as a measure of workforce permanence, the present study employs a measure of the years the establishment has been in operation in regressions using training diversity, as well as those using training volume, as the dependent variable.

Industry sector is also regarded as an important explanatory factor that influences the provision of enterprise training. In the studies conducted by Smith et al (2002), Hayton et al. (1996) and Ridoutt et al. (2002), for instance, both the nature and the extent of training activity was found to vary across product markets. In the present study, therefore, enterprises are grouped in terms of the foremost Australian New Zealand Standard Industry Classification (ANZSIC) industry grouping in which they produce output. The broad categories we employ in this regard are essentially the 1-digit ANZSIC industry groupings, which encompass more precisely defined industry categories as follows: the primary industries are agriculture, forestry and fishing, and 
mining; the secondary industries are manufacturing; electricity, gas and water; and construction; and, the tertiary industry category encompasses wholesale and retail trade, accommodation, cafes and restaurants, transport, storage and communication, finance and insurance, property and business services, education, health and community services, and cultural and recreational services.

Dummy variables for firms in the information and communications technology (ICT) and tourism sectors are the two exceptions to this broad grouping of industries. The former is distinguished from the broad industry categories due to the importance of skill development in the work performed by many of those employed in this sector. The latter is included as a separate category for the simple reason that, in addition to classification using the ANZSIC system, the Business New Zealand survey respondents asks respondents if they consider their enterprise to be in the tourism sector, to which 12 percent answered in the affirmative. It is also important to note that ICT is not included as a specific response option in the questionnaire item related to industry sector. As a consequence, organisations identified by respondents to this survey as falling predominantly in this sector are so identified only when the survey respondent used the "other industry" option included for this item on the survey questionnaire and specifically identified in writing ICT as that other industry.

With regard to establishment size, the extant literature on training and development points to a strong, positive correlation between the number of employees, and the nature and extent of training provision (Blundell, Dearden \& Meghir 1996; Hayton et al., 1996; Groot, 1997; OECD, 1999). It is argued that small to medium sized enterprises are disadvantaged, as they often do not have an internal person dedicated to training activities (NECA, 1998, as cited in Ridoutt et al, 2002). Moreover, due to the costs involved or the fact that such activities do not directly support the organisation's limited business activities, formal training and education initiatives are often deemed inappropriate by management for employees of small business enterprises.

In addition, one recent study found no relationship between the size of the worksite and training volume (Ridoutt et al., 2002). This suggests that the number of employees in an enterprise may influence the nature of training (i.e. training reform engagement, reliance on external providers, and training formalisation) but not the extent of training. Moreover, other research has shown that the relationship between enterprise size and training activity is not linear. That is, it is not simply the case that smaller enterprises typically support relatively little training and larger enterprises offer relatively more training. Rather, training activity has been shown to be context-specific and, hence, expressed in different ways in each organisational situation. For example, an individual worksite which is part of a larger organisation may have differing training demands than other worksites within that organisation or the organisation as a whole (Hayton et al., 1996).
For purposes of the study, as is typical this literature, establishment size is measured by number of employees in an enterprise. The survey instrument employed in this analysis further disaggregates the total number of employees by full- and part-time status, and casual and permanent employment, as well as providing the share of the workers in the organisation who are female. As such, a measure of each of these factors is also included in our statistical analysis. In terms of casual and part-time workers, research from Australia (Austen, 1995; VandelHuevel and Wooden, 1999), Britain (Arulapalam and Booth, 1998), and several other OECD countries (OECD, 2000) suggests that these employees receive less training than their full-time and permanent counterparts.

It is perhaps of interest, as well, that, in our sample data, the percentage of employees who are female is highly correlated $(0.45)$ with the relative number of part-timers working in the organisation, although the correlation between use of part-time and casual workers in much lower $(0.23)$. This suggest that, while gender may be a significant determinant of support for training and development by these organisations, finding evidence to support this conclusion may prove problematic due to multicollinearity between our gender and part-time variables. In a similar sense, because some industries are known to make greater use of casual employees than others, inclusion of industry dummies along with a measure of casualisation may confound the results, in particular, for the latter.

Variables included in this analysis related to skill and qualifications are weighted measures of, respectively, skill levels and formal qualifications earned by employees of an organization. The share of the organization's employees with only a school qualification is given a weight of 1 ; the percentage of employees of the organization with a technical qualification and that of employees with a certificate/diploma qualification are each provided a weight of 2.5 ; and, the share of employees with a degree qualification is weighted by a factor of 4 . The proportion of employees with no school qualification is not included in the calculation of this measure. Similarly, the share of the organization's employees with simple skill level is given a weight of 1 ; the percentage of employees of the organization with moderate skill level and that of employees with complex/technical skill level are provided a weight of 2 and 3 , respectively; and, the share of employees with a complex skill level is weighted by a factor of 4 .

Variables measuring the concentration of skills and qualifications are specified as a Herfindahl-Hirschman Index ( $\mathrm{HHI})$, which is most commonly used as a measure of product market concentration. These measures are calculated, for purposes of this analysis, by squaring the share of a sample organization's employees in each skill or qualification category, and then summing the squared values. In this case The $\mathrm{HHI}$ can range from a minimum of 0.5 and 0.4 , respectively, where one quarter of the employees of an organization fall into each of the four skill and one fifth of the employees of an organization fall into each of the five qualification categories, to a maximum of 1.0, where all employees fall into a single 
skill or qualification category. In this regard, then, higher values of reflect greater skill of qualification concentration - i.e., less spread or variation in skill or qualification levels - among the employees of the organization. Alternatively, lower HHI values are an indicator of more diversified skill levels and qualifications within the organization.

\section{Data Summary}

Tables 1 and 2 offer a list of the measures employed in the analysis described in the following section of this paper. The former provides a breakdown of the 467

\section{Table 1}

Descriptive Statistics: Organisational Characteristics

\begin{tabular}{|c|c|c|}
\hline $\begin{array}{c}\text { Organisational Characteristic } \\
\text { (Total } N=467 \text { ) }\end{array}$ & $\begin{array}{c}\text { Sample } \\
\text { Proportion }\end{array}$ & $\mathbf{N}$ \\
\hline \multicolumn{3}{|l|}{ Years of Operation } \\
\hline Less than 2 years & $2.6 \%$ & 12 \\
\hline $2-5$ years & $10.1 \%$ & 47 \\
\hline 6-10 years & $17.6 \%$ & 82 \\
\hline $11-20$ years & $25.5 \%$ & 119 \\
\hline $21-50$ years & $25.7 \%$ & 120 \\
\hline $51+$ years & $18.6 \%$ & 87 \\
\hline \multicolumn{3}{|l|}{ Industrial Category } \\
\hline Tourism (not mutually exclusive) & $12.0 \%$ & 55 \\
\hline Information and Communication Technology & $2.4 \%$ & 11 \\
\hline Primary Industry & $8.1 \%$ & 38 \\
\hline Secondary Industry & $34.0 \%$ & 159 \\
\hline \multicolumn{3}{|l|}{ Location } \\
\hline Auckland & $22.1 \%$ & 103 \\
\hline Bay of Plenty & $5.1 \%$ & 24 \\
\hline Canterbury / West Coast & $31.0 \%$ & 145 \\
\hline Gisbourne / Hawkes Bay & $2.6 \%$ & 12 \\
\hline Nelson / Marlborough & $1.9 \%$ & 9 \\
\hline Northland & $1.3 \%$ & 6 \\
\hline Otago / Southland & $10.1 \%$ & 47 \\
\hline Taranaki / Wanganui / Manawatu & $2.4 \%$ & 11 \\
\hline Waikato & $8.8 \%$ & 41 \\
\hline Wellington / Wairarapa & $4.5 \%$ & 21 \\
\hline National & $10.3 \%$ & 48 \\
\hline
\end{tabular}

establishments for which all items used in this analysis were provided by respondents to the 2003 Business New Zealand Survey. The latter includes measures describing characteristics of employees of those organisations.

As can be seen in Table 1, the vast majority of enterprises included in the study sample have spent more than a decade in operation. Most are in the tertiary sector, although more that 1 in 10 of the respondents define their business as being related to tourism, which encompasses organisations in one of the other industry categories as well. These data also reveal that, while more than half of these organisations are located either in or around Auckland or in the Canterbury or West Coast regions of New Zealand's South Island, just over 10 percent of operate on a national basis.

Employee demographics of the enterprises included in this analysis are presented in Table 2 . While these are rather straightforward, it is noteworthy that the average (mean) establishment size in this sample is grater than
100 employees, with a standard deviation of more than 325. These statistics are even more conspicuous given that the former is obviously truncated at the lower level at 1. What this suggests, as has previously been noted, is that enterprises in this sample are typically much larger in size than true of New Zealand employers in general or of establishments at which the typical New Zealand worker is employed.

Table 2

\section{Descriptive Statistics: Employee Demographics}

\begin{tabular}{|c|c|c|}
\hline $\begin{array}{l}\text { Employee Demographic } \\
\quad(\text { Total } N=467)\end{array}$ & $\begin{array}{l}\text { Sample } \\
\text { Statistics }\end{array}$ & $\mathbf{N}$ \\
\hline No. of Employees: Sample mean (std deviation) & $102.4(326.2)$ & 456 \\
\hline Female (\%) & $43.0 \%(28.1 \%)$ & 432 \\
\hline Full-time (\%) & $78.6 \%(24.5 \%)$ & 451 \\
\hline Part-time (\%) & $15.1 \%(20.2 \%)$ & 450 \\
\hline Casual (\%) & $7.1 \%(15.4 \%)$ & 445 \\
\hline \multicolumn{3}{|l|}{ Qualifications: $\%$ of sample in each category } \\
\hline No School Qualification & $18.2 \%$ & 436 \\
\hline School Qualification & $30.5 \%$ & 436 \\
\hline Trade Qualification & $16.4 \%$ & 436 \\
\hline Certificate / Dipolma Qualificiation & $17.2 \%$ & 436 \\
\hline Degree Qualification & $17.2 \%$ & 436 \\
\hline \multicolumn{3}{|l|}{ Skill Levels: \% of sample in each category } \\
\hline Simple skill level (little experience required) & $16.8 \%$ & 349 \\
\hline $\begin{array}{l}\text { Moderate skill level (some experience required, } \\
\text { qualification desirable) }\end{array}$ & $33.6 \%$ & 352 \\
\hline $\begin{array}{l}\text { Complex / technical skill level (a number of } \\
\text { years experience and qualification normally }\end{array}$ & $31.5 \%$ & 354 \\
\hline $\begin{array}{l}\text { Very high skill level ( } 5 \text { years experience and a } \\
\text { formal qualification essential) }\end{array}$ & $18.6 \%$ & 354 \\
\hline
\end{tabular}

This potential source of bias notwithstanding, other figures reported in Table 2 indicate that employees of the establishments encompassed in this sample generally fall within the known demographics of the country's labour force as a whole. For instance, women comprise 43 percent of employees of the sample establishments, compared to the 45.4 percent of workers in the country's labour force that is female, as ascertained from Statistics New Zealand's March 2003 Household Labour Force Survey (HLFS). Similarly, full-time employees comprise 78.6 percent of employees covered in the sample, which corresponds with the 77.3 percent figure for the total working population in New Zealand derived from the March 2003 HLFS. Furthermore, in terms of qualifications, the figure of 18.2 percent in Table 2 for the share of those employed by establishments in the sample with no school qualification is not significantly different from the 18.7 percent figure for the New Zealand population as a whole reported by New Zealand's Department of Statistics for 2003. (Statistics New Zealand, 2003).

\section{Results and Discussion}

To analyse the data described in the previous sections of this paper, log-linear regressions, are run after transforming each variable into a natural log scale. Variables in percentage form are not logged in these regressions for two reasons. First, as a percentage approaches zero, its log approaches negative infinity. In 
addition, though, by using percentage, the data have already been transformed into log-form equivalents. Similarly, because the natural $\log$ of 1 is 0 and the natural $\log$ of 0 is undefined, it is not possible to take the natural log of a dummy variable. Hence, dummy variables-i.e., categorical variables among the independent variables that have been 'binarised' into k-1 dummies for $k$ categories - are also not logged in these regressions.

Results of these regressions are reported in Table 3. The reader will note that not all of the variables discussed in the previous sections have been included in these regressions. Among the variables omitted from the results reported here are dummy variables for enterprise location. These, in fact, have intentionally been excluded from these regressions since very little is revealed in the extant literature regarding the impact of geographical location on employer investment in training and development. Hence, the fact that regressions conducted for this analysis although not reported here yielded no statistically significant findings for this relationship is not surprising.

In addition, the measures of skill and qualifications derived from the Business New Zealand survey are highly collinear, Specifically, the correlation between our measures of employee skill level and qualifications earned by employees of the organization is 0.64 , and the correlation between the two $\mathrm{HHI}$ measures of the concentration of skill levels and qualifications is 0.43 . For this reason, the two measures of employee qualifications-i.e., the index of average qualification level achieved by employees of the organisation and the concentration of those qualifications within the organisation-have been dropped from the regressions for which results are reported in Table 3 .

These statistics explain why, in regressions that include the two measures of skill and the two measures of qualifications, none of the coefficients on any of these variables is statistically significant. However, regressions where only the two measures of skill or only the two measures of qualifications are specified yield results which are significant at the .01 alpha level. Moreover, coefficient estimates from the latter regressions are quite similar in magnitude. That is, these estimates are similar irrespective of whether we include the two measures of skills or the two measures of qualifications in our regression models. For these reasons, only those results using the former are reported herein.

What the findings reported here do suggest is that, while training investment varies significantly across industries, the age of the enterprise is a far more important determinant of training diversity in New Zealand enterprises. With regard to the former, results reported in the second column of Table 3 point to the conclusion that New Zealand firms in the primary and secondary sectors as well as firm in the tourism industry invest significantly less in training than do those in the ICT and tertiary sectors. In terms of training diversity, given that firms less than two year in operation are included in the referent (omitted) eategory in this regard, estimates found in the
Table 3

\section{Regression Estimates}

\begin{tabular}{|c|c|c|}
\hline Dependent Variable & $\begin{array}{c}\text { Training Volume } \\
\text { (Extent) }\end{array}$ & $\begin{array}{c}\text { Training Diversity } \\
\text { (Nature) }\end{array}$ \\
\hline Mean & 1.584 & 0.902 \\
\hline Standard Deviation & 2.503 & 1.273 \\
\hline Independent Variable & Coef (Std Err) & Coef (Std Err) \\
\hline $\begin{array}{l}\text { Constant } \\
\text { Years of Operation }\end{array}$ & $1.266(0.373)^{\star \star *}$ & $0.661(0.265)^{\star *}$ \\
\hline$<2$ years & \multicolumn{2}{|c|}{ Omitted/referent category } \\
\hline $2-5$ years & $-0.051(0.301)$ & $0.200(0.217)$ \\
\hline $6-10$ years & $0.15(0.290)$ & $0.391(0.209)^{\star}$ \\
\hline $11-20$ years & $-0.029(0.291)$ & $0.474(0.209)^{\star *}$ \\
\hline $21-50$ years & $0.032(0.289)$ & $0.463(0.208)^{\star *}$ \\
\hline $51+$ years & $0.133(0.289)$ & $0.459(0.209)^{\star *}$ \\
\hline \multicolumn{2}{|l|}{ Industry } & Omitted/referent category \\
\hline Primary & $-0.356(0.165)^{\star *}$ & $-0.043(0.107)$ \\
\hline Secondary & $-0.249(0.129)^{*}$ & $0.079(0.088)$ \\
\hline Tertiary & $-0.142(0.130)$ & $0.009(0.089)$ \\
\hline Tourism & $-0.209(0.075)^{* * *}$ & $-0.099(0.047)^{\star *}$ \\
\hline \multicolumn{3}{|l|}{ Demographic } \\
\hline \# of Employees & $0.013(0.019)$ & $0.054(0.013)^{\star \star \star}$ \\
\hline Female $(\%)$ & $0.155(0.110)$ & $0.086(0.077)$ \\
\hline Part-time (\%) & $-0.437(0.176)^{\star *}$ & $-0.331(0.104)^{\star * *}$ \\
\hline Casual $(\%)$ & $-0.337(0.128)^{\star \star \star}$ & $0.185(0.087)^{\star \star}$ \\
\hline Skills & $0.150(0.048)^{\star \star \star}$ & $0.101(0.033)^{* * *}$ \\
\hline Skill Concentration & $-0.739(0.209)^{\star \star \star}$ & $-0.407(0.143)^{\star \star \star}$ \\
\hline $\mathbf{N}$ & 239 & 312 \\
\hline $\mathbf{R}^{2}$ & 0.42 & 0.39 \\
\hline Adjusted $R^{2}$ & 0.35 & 0.34 \\
\hline Prob $>$ F & 0.00 & 0.00 \\
\hline
\end{tabular}

third column of Table 3 suggest that, relative to those newer organisations, on average, New Zealand organisations in operation for more than 5 years offer between 47.9 and $60.6 \%$ more diversified training opportunities to their employees

Bearing in mind that ICT is the referent (omitted) category in these regressions, the results from the training volume regression imply that training volume in New Zealand firms in the primary industries is, on average, 30 percent less than in firms in the ICT sector. Moreover, training volume in New Zealand firms in the secondary industries and the tourism sector is estimated to be, respectively, 22 and 18 percent less than in ICT firms. However, there appears to be no statistically significant difference in the extent of training supported by firms in the tertiary and ICT sectors.

In terms of New Zealand employers' willingness to invest in the training of part-time and casual workers, the coefficient in the second column of Table 3 on the former variable implies that, all else equal, for every 1 percent increase in the share of an organisation's workers who work on a part-time basis, the organization will invest, on average, 43.7 percent less on training. Similarly, the coefficient estimate on the variable measuring the relative share of casual employees hired suggests that a 1 percent increase in this factor will lead, on average, to a 33.7 percent decrease in training volume. 
Certainly, in the case of casual employees, this finding is not surprising, given that organsations are not likely to make investments from which they are unlikely to reap benefits in the future. With regard to part-time employees, though, this result suggests that employers in New Zealand tend to view these workers as peripheral in perhaps a similar way as they view their casual workforce. Alternatively, this may simply suggest that employers in New Zealand do not feel part-timers will tend to log enough hours on the job following any training they receive to compensate for the cost of such an investment.

Among the key findings from this analysis, however, are those related to the importance of skill levels and the concentration of skills possessed by employees on both willingness to invest in training and the diversity of those investments supported by the organizations included in this sample. These results suggest that New Zealand organizations invest more in training and support more training options when they employ a more skilled workforce and when the skills of those workers employed are more varied.

The reader will recall that the skills variable is a weighted measure ranging from 0 to 4 which gauges the proportion of employees falling into the various skill categories described earlier in this paper and that the skill concentration variable is specified as a HerfindahlHirschman Index (HHI). In this regard, then, the coefficient on the skills variable in the second column of Table 3 implies that every 0.1 unit increase in the average skill level of the organisation's workforce will affect a $1.5 \%$ increase in training volume supported by that organisation. The skills concentration coefficient found in this same column of Table 3 suggests that every 0.1 unit increase in the concentration of skills among employees of the organisation will affect a $7.4 \%$ decrease in training volume in the typical sample organisation.

The results for training diversity in column 3 of this table are interpreted similarly. That is, the coefficient for the effect of average skill level on the nature of training implies that every 0.1 unit increase in average skill level will affect a 1 percent increase in training diversity in the typical sample organisation. The coefficient of the $\mathrm{HHI}$ for skills concentration in this column suggests that every 0.1 unit increase in the concentration of skills amongst employees of the organisation will affect a 4.1 percent decrease in training diversity in the typical sample organisation.

Another interesting finding from this analysis is that gender appears to play no role in whether and how much an employer invests in training nor in how diversified the training options supported by the employer are. However, it's worth noting in this regard that, whereas these coefficient estimates are not statistically significant in the regressions reported in Table 3, the gender coefficient is statistically significant and negative in regressions employing measures of qualifications and the concentration of qualifications among employees of the organization. This may imply that women are more likely to earn qualifications that are not valued in the labour market as much as those typically achieved by men. Such a conclusion is supported by evidence from the 2001 New Zealand Census indicating that 22 percent of New Zealand women, compared to only 5 percent of men, had earned a post-school qualification in the generally lower paying health field, while engineering and related technology was the choice of 33 percent of men but only 2 percent of women in New Zealand. These results may also suggest that work experience, the other factor along with qualifications earned comprising the measures of skill in these regressions, tends to mitigate the effect of gender on the likelihood an employer will invest in and diversify the training of its employees.

It might also interest the reader to know that regressions using a subsample of the data excluding organisations in the government and education sectors yield estimates which do not vary significantly from those derived from regressions using the full sample. In addition, regressions using a subsample of only those organizations in the government and education sectors, where industry and year dummies are excluded due to the fact that these variables are perfectly collinear in these regressions, provide generally insignificant results. No doubt, the reason for these outcomes lies in the fact that organizations in the government and education sectors comprise less than 10 percent of the study sample $(\mathrm{n}=45)$-i.e., 2.6 and 7.1 percent, respectively-and, in turn, the overall sample $(n=467)$ is dominated by organizations included in the larger of these two subsamples.

Furthermore, we also ran regressions using more disaggregated industry measures than those manifest in the tables presented herein. While these ANZSIC dummies showed to be statistically significant in some regressions, the sign and estimated value of these coefficients indicated that their impact on the respective dependent variables was similar within the broad industry groupings. Therefore, for the most part, only the latter are used in the statistical results presented in this paper. Again, the two exceptions to this general rule are the dummy variables specified for firms in the ICT and tourism sectors.

In addition to industry sector, other studies have considered ownership structure among factors thought to influence the level of training in enterprises. Yadapadithaya (1999), for instance, found that ownership patterns influences management's perception of competition and, in turn, affects how management views the role of employee training and development in the context of workplace change, quality management and organisational culture. Responses to a question in the Business New Zealand Skills and Training Survey in reference to the nature of the enterprise indicate that close to two-thirds of the organisations surveyed are private limited liability companies, that fewer than 10 percent are public companies, and that government enterprises account for 5 percent of the organisations surveyed. However, this survey fails to distinguish multinational firms and joint-venture alliances, ownership categories found elsewhere to be significant and positive determinants of training provision (e.g., Yadapadithaya, 
1999; Ridoutt et al, 2002). Moreover, results derived from (unreported) regressions using the various ownership categories used by Business New Zealand yielded no significant estimates of ownership effects. For these reasons, measures of these variables are excluded from both the descriptive statistics and regressions reported herein.

\section{Summary and Conclusions}

A number of conclusions can be drawn from the analysis presented herein. First, not surprisingly, New Zealand employers invest more in employee training and offer a wider variety of training options when they employ a more skilled workforce. This finding is supported by a plethora of literature which suggests that training opportunities generally accrue to better skilled and more qualified employees (Blundell, Dearden and Meghir, 1996; Groot, 1997; Blandy Dockery, Hawke and Webster, 1997).

The extant research, though, also highlights somewhat of a saturation effect. That is, it is typically the case that the total number of hours of training provided or supported by an organisation is reduced commensurate with the higher the level of skill and qualifications acquired by those employees receiving or potentially receiving that training (Blandy et al., 1997). Hence, it also would not necessarily have been surprising to find, at least in some organisations included in this study, higher levels of skill to be associated with lower levels of investment in training and diversity of training options. This, in fact, may serve to explain why greater concentration of skill levels within an organisation were found in this study to be associated with lower training investment and fewer training options. That is, if these skills are, in general, concentrated at higher levels, these findings may suggest the presence of a saturation effect.

Another key - albeit, again, not surprising - finding from this study is that New Zealand organisations in the ICT and tertiary sectors tend, on average, to support more training than firms in this country's primary, secondary and tourism sectors. What the findings reported here also suggest, though, is that the amount of time the organisation has been in operation is far more important than industry sector in determining the level or extent of training diversity in New Zealand enterprises. In addition, it is important to note that casualisation of work is associated with decreased overall investment in training, notwithstanding the fact that this factor is also found to increase the diversity of training options offered in New Zealand organizations.

Finally, establishment size, measured in terms of the number of employees, is generally found to influence provision of training in enterprises and is often noted as a significant explanatory variable in the literature (OECD, 1999: Blundell, Dearden and Meghir, 1996; Groot, 1997; Blandy Dockery, Hawke and Webster, 1997, Smith and Hayton, 1999; Ridoutt et al, 2002; Smith et al, 2002). However, there isn't a linear relationship between size, as represented by the number of employees and, the nature and extent of training, as each enterprise has its unique training needs. Thus, it is likely that dependant variables such as diversity of training arrangements will have a significant relationship, as was found in this study. It is unlikely that the same is true for other dependent variables, such as volume of training, expressed as percentage of payroll. Again, results of this study confirm this.

Overall, results of this analysis suggest, among other things, that firm size and casualisation of workforce are the most significant factors affecting the provision of training by New Zealand employers. Nonetheless, due to the manner in which the source of data employed in this analysis, Business New Zealand's 2003 Skills and Training Survey, was designed, a number of key variables identified in the literature, such as adoption of new management practices like total quality management, the learning organization, team working, lean production, business process restructuring, as well as regulatory factors and alignment of business strategy to the organization's human resource management strategy (Smith et al, 2002) were not considered in our analysis. An important consideration in this regard is that these omitted variables may have a masking effect on the findings from this study as elaborated in this paper. This, in turn, suggests directions for future research in this area.

\section{References}

Arulampalam, W. and Booth, A. (1998) Training and labour market flexibility: Is there a trade-off? British Journal of Industrial Relations. Vol. 36(4), 521-534

Austen, S. (1995). The growth in part-time employment: Implications for training policy. Western Australia Department of Training Perth.

Blundell, R., Dearden, L. \& Meghir, C. (1996) The determinants and work related training in Britain. Institute of Fiscal Studies: London.

Business New Zealand and Industry Training Federation of New Zealand (June 2003). Report of the Business New Zealand Skills and Training Survey 2003. Future of Work Programme, Department of Labour: Wellington.

Campbell, I (2001). Casual employees and the training deficit: Exploring employer calculations and choices. International Journal of Employment Studies. Vol. 9(1), 61-102.

Field, L (1998). 'Shifting the focus of 'training' to 'learning': The case of Australian small business.' ANew Zealand Journal of Vocational Education and Research, Vol (6) 1, pp. 49-69.

Garavan, T.N. (1997a) 'Training, development, education and learning: different or the same?', Journal of European Industrial Training, 21(2):3950 .

Garavan, T. N., Gunnigle, P. and Morley, M. (2000) 'Contemporary HRD research: A triarchy of 
theoretical perspectives and their prescriptions', Journal of European Industrial Training, 24(1,2,3,4): 65-93.

Groot, W. (1997). Enterprise related training: A survey. ACER, Monash University: Melbourne

Hayton, G., McIntrye, J., Smart, R., McDonald, R., Noble, C., Smith, A., and Roberts, P. (1996) Final Report: Enterprise Training in Australia. Melbourne: Office of Training and Further Education and Brisbane, Australian National Training Authority.

Long, M., Ryan, R., Burke, G., and Hopkins, S. (1999) Enterprise-based education and training: A literature review. Melbourne: ACER Centre for the Economics of Training and Education (Unpublished).

NCEA (1998) Barriers to the employment of apprentices in the electrical, electronic and communications industry: A study of training needs and reform. NECA, Melbourne. OECD/CERI, (1986) New technology and HRD in the automobile industry. Paris: OECD Mimeograph.

OECD/CERI, (1988) Human resources and corporate strategy: Technology change in banks and insurance companies. Paris: OECD.

OECD (1999). 'Training of adult workers.', Employment Outlook, June, OECD: Paris.

OECD (2000) Employment Outlook. Paris
Prais, S.J. \& Steedman, H. (1986). Vocational training in France and Britain: The building trades. National Institute of Economic Review, Vol. 116, May, 45-55.

Ridoutt, L., Dutneall, R., Hummel, K, and Smith, C.S. (2002) Factors influencing the implementation of training and learning in the workplace. Leabrook, SA: NCVER.

Smith, A., and Hayton, G. (1999) 'What drives enterprise training? Evidence from Australia', The International Journal of Human Resource Management, 10(2): 251-272.

Statistics New Zealand (2003) Labour Market Statistics 2003 (Department of Statistics: Wellington)

Stevens, J., and Walsh, T. (1991) Training and Competitiveness. In Stevens, J. and Mackay, R. (eds) Training and Competitiveness. London: Kogan Page.

VandelHeuvel, A. and Wooden, M (1999). Casualisation and outsourcing: Trends and implications for work-related training. NCVER, Leabrook, SA.

Yadapadithaya, P.S. (1999) "HRD Policies and Practices in Indian Industries." Unpublished research Monograph, Mangalore University 